\title{
A Santa Casa da Misericórdia do Rio de Janeiro nos séculos XV a XIX
}

\section{Rio de Janeiro's Holy House of Mercy from the $16^{\text {th }}$ to the $19^{\text {th }}$ centuries}

\author{
Luciana Mendes Gandelman \\ Mestre em história pela Universidade Estadual de Campinas (Unicamp) \\ com dissertação sobre o recolhimento das órfãs da Santa Casa da Misericórdia \\ do Rio de Janeiro e a caridade para com as mulheres (1739-1830) \\ Rua Belisário Távora, 181/102 \\ 22245-070 Rio de Janeiro - RJ \\ lucianam@ism.com.br
}

\begin{abstract}
Este artigo tem como objetivo apontar as principais transformações ocorridas no espaço e nos prédios da irmandade da Santa Casa da Misericórdia do Rio de Janeiro da sua fundação até o século XIX, relacionando-as a alguns dos possíveis significados sociais dessas mudanças.
\end{abstract}

PALAVRAS-CHAVE: caridade e assistência social, irmandade leiga, Santa Casa da Misericórdia, Rio de Janeiro, transformações sociais e instituições.

The present articleaims at showing the main changestaken place in the buildings and the surrounding areas of Rio de Janeiro's Holy House of Mercy from its foundation to the $19^{\text {th }}$ century, relating them to some of the possible social meanings of such changes.

KEYWORDS: charity and social assistance, lay brotherhood, Holy House of Mercy, Rio de Janeiro, social changes and institutions.

...Foi a primeira rua do Rio. Dela partimos todos nós; nela passaram os vice-reis, os malandros, os gananciosos, os escravos nus, os senhores em redes; nela viajou a imundície, nela desabotoou a flor da influência jesuítica. ... Dela brotou a cidade no antigo esplendor do largo do Paço, dela decorrem, como de um corpo que sangra, os becos humildes e os coalhos de sangue, que são as praças ribeirinhas do mar. Mas soluço de espancado, primeiro esforço de uma porção de infelizes, ela continuou pelos séculos afora, sempre lamentável e tão angustiosa, franca e verdadeira na sua dor, que os patriotas lisonjeiros e os governos, ninguém, ninguém, se lembrou de lhe tirar das esquinas aquela muda prece - aquele grito de mendiga velha - Misericórdia!

Paulo Barreto ${ }^{1}$

\footnotetext{
${ }^{1}$ Citação a Paulo Barreto, sem referência, utilizada por Noronha Santos (1981, p. 87), na introdução às memórias do padre Perereca.
} 
$A$ s belas palavras de João do Rio escolhidas para descrever a rua da Misericórdia bem poderiam ser utilizadas para descrever a própria Santa Casa da Misericórdia que, de sua ermida ao sopé do morro do Castelo, fez parte da história da cidade do Rio de Janeiro desde o seu primeiro século. Atualmente, olhando para os prédios e enfermarias da Santa Casa, e seus corredores, tomados na movimentação apressado dos médicos preocupados com a vida dos corpos, muito facilmente nos esquecemos de que a Misericórdia começou como irmandade de devoção a Nossa Senhora da Misericórdia, construída ao redor de uma igreja, e que os corpos eram curados no vai-e-vem de devotos e seus pedidos à Mãe e Advogada dos homens, os corações apreensivos com a vida da alma.

A irmandade de Nossa Senhora da Misericórdia foi criada em Portugal, no ano de 1498, por dona Leonor, irmã de d. Manuel, sob a influência do frei trinitário Miguel de Contreiras. A irmandade organizava-se em torno das chamadas 14 obras de caridade, sete espirituais e sete corporais, inspiradas pelo Evangelho consignados segundo são Mateus, e no primeiro Compromisso de 1516, a saber: "ensinar os ignorantes, dar bom conselho, punir os transgressores, consolar os infelizes, perdoar as injúrias recebidas, suportar as deficiências do próximo, orar a Deus pelos vivos e mortos, resgatar cativos e visitar prisioneiros, tratar os doentes, vestir os nus, alimentar os famintos, dar de beber aos sedentos, abrigar os viajantes e os pobres, sepultar os mortos" (Russell-Wood, 1981, pp. 14-5). Seu âmbito de atuação, portanto, correspondia a esferas bem mais amplas do que o que hoje entendemos como sendo as de um hospital. Contando com patrocínio régio, a Santa Casa espalhou-se rapidamente pelo império português, tornando-se a irmandade leiga de maior poder e expressão no que concerne às obras de caridade. Tornou-se uma marca da colonização portuguesa. Segundo Isabel dos Guimarães Sá (1995, p. 100), antes de 1750 já havia, além das inúmeras Misericórdias em Portugal, 11 nas ilhas de Açores e Madeira, 3 em Angola, 29 por toda a Ásia e 16 somente no Brasil. As Misericórdias de maior poderio em terras brasílicas foram as do Rio de Janeiro e da Bahia, centros vitais do projeto colonizador português.

A criação da irmandade na cidade do Rio de Janeiro é uma incógnita para historiadores e memorialistas. Segundo o relato de frei Agostinho de Santa Maria impresso em 1723, em um dos volumes do Santuário Mariano, a irmandade teria sido criada por iniciativa do jesuíta José de Anchieta após a chegada à cidade, "pelos anos de 1582", de uma armada de Castela composta por 16 naus e três mil homens. Enfrentara muitas intempéries na viagem e por isso chegou ao porto repleta de doentes. Segundo o padre Simão de Vasconcellos (1906, p. 7), aquela visita repentina provocou grande pânico na população, que tratou de pôr a salvo seus pertences. Quando as naus ancoraram na baía, achava-se na cidade, em visita ao Colégio dos Jesuítas, o padre José de Anchieta que "levado da caridade tomou muito por sua conta a cura, e o remédio daqueles enfermos", destinando-Ihes uma casa para seu tratamento, com a ajuda de alguns religiosos, "assistindo também ele ao mais as medicinas, médico e cirurgião" (Santa Maria, 1723, pp. 9-10).

Assim teria surgido o hospital da cidade, assumindo os irmãos da Santa Casa a tarefa de cuidar dos doentes,

o que fizeram com grande caridade, e o foram aumentando no material com tanta grandeza, e tão perfeitas enfermarias, como hoje se vêem, aonde se curam todos os enfermos de um e outro sexo com exímia caridade. ... Desde este tempo continuaram os provedor e irmãos no serviço e administração do hospital, assistindo com suas esmolas, e dos mais fiéis, que em seus testamentos as deixaram, assim para o culto divino, como para o aumento da Casa e cura dos pobres enfermos e desamparados. 
A irmandade receberia provisão da Misericórdia concedida por Felipe II no ano de 1605, contando a partir de então com "todos os privilégios e graças, honras e liberdades que têm e gozam as casas" (Ferreira, 1894-98, p. 89) de Lisboa e Setúbal. Na petição, enviada ao rei, os irmãos requerentes descreviam a instituição que "há sessenta anos tem feito casa com seu hospital para enfermos, sacristia e parlatório". A Misericórdia era então uma Casa na qual se articulavam as ações de caridade guiadas pelos preceitos cristãos e pelas relações de Antigo Regime. 0 conjunto arquitetônico da Misericórdia foi sendo construído e reconstruído aos poucos, sempre circundante à igreja, em cujo consistório os irmãos faziam suas reuniões. De lá partiam grande parte dos serviços e dos recursos oferecidos pela irmandade. Era seu cerne simbólico. Segundo a descrição de frei Agostinho, a igreja era formosa, ricamente ornamentada e servida "com muito mais grandeza e autoridade" (Santa Maria, 1723, p. 11) que a catedral. Para a capela de Nossa Senhora do Bom Sucesso, que se tornaria a padroeira da irmandade somente em 1713, acorriam, segundo o frei, "todos os moradores daquela cidade em seus trabalhos e tribulações, nas suas doenças perigosas sempre acham em tudo alívio, socorro, o remédio, e em muito bom sucesso".

0 passo das construções seguia lento à medida que se angariavam recursos entre homens ávidos por garantir a salvação de suas almas, por investir parte de seu capital no prestígio social da instituição e de si próprios. A Casa da Santa Misericórdia, como também era conhecida, situava-se no tempo de frei Agostinho "muros adentro daquela cidade", na base do morro do Castelo, justamente onde se iniciara o povoamento do Rio de Janeiro. Dali a Misericórdia observaria a cidade crescer e modificar-se, transformando as necessidades médicas e sociais que seria chamada a satisfazer.

Como podemos observar pela petição de 1605 , na qual os irmãos pediam a Felipe II carta de Misericórdia, as atividades iniciais da irmandade giravam em torno da manutenção do hospital para enfermos, do casamento de órfãs, da distribuição de esmolas e de "ordinárias", estas aos sábados. Proporcionavam alívio aos doentes nas enfermarias e capelas, num tempo em que os perigos mais graves do corpo deveriam ser enfrentados com a cura das almas. A Misericórdia cuidava também dos sepultamentos. Apesar de não serem mencionados explicitamente no documento, tornar-se-iam uma das funções mais importantes da instituição, uma vez que as cerimônias de enterro assim como o local de sepultura eram meios importantíssimos de garantir uma "boa morte", ou seja a vida da alma. ${ }^{2}$

Nas primeiras décadas do Setecentos as atividades da irmandade passaram por modificações que acarretaram mudanças em seu espaço. Deixou de ser a irmandade da "cidade-fortificação", encarregada principalmente dos contingentes flutuantes vindos nas naus e fragatas, para voltar-se para os habitantes de uma aglomeração urbana em rápido desenvolvimento, com problemas sociais diversos. No século XVIII, o escoamento do ouro fortaleceu a praça do Rio de Janeiro, aumentando o fluxo de recursos e a densidade populacional da cidade. A pressão por auxílio social tornou-se mais forte. Por outro lado, aumentaram os recursos disponibilizados pelos mercadores, uma parcela da população sedenta de afirmação social. Dois provedores foram de grande importância para as transformações sofridas pela irmandade, por conseguirem aglutinar membros dessa camada social e atrair suas doações. Foram eles o dr. Manuel Corrêa Vasques, provedor de 1732 até 1741, e Antônio Telles de Menezes, que ocupou o cargo apenas no período de 1735-36.

\footnotetext{
${ }^{2}$ Sobre a importância da "boa morte" e o significado dos rituais de enterramento, ver Reis (1999) e Rodrigues (1997).
} 
Durante a provedoria destes dois "homens bons", envolvidos na governança da cidade, 0 grupo de irmãos que lideravam se dispôs a financiar obras e vários empreendimentos caritativos inexistentes até então.

Graças aos recursos desse grupo, que Vieira Fazenda (1960, p. 97) denomina "milicianos da caridade", várias obras foram feitas na irmandade. Por exemplo, a reforma do altar de Nossa Senhora do Bonsucesso, um segundo andar no hospital e, principalmente, a criação do Recolhimento das Órfãs e a Casa dos Expostos. Em 1738, Romão de Mattos Duarte deixou 32 mil cruzados para a compra de casas e sustentação permanente dos expostos com seus rendimentos. ${ }^{3}$ No mesmo ano, Inácio da Silva Medella doou 15 moradas de casas e 1:600\$000 réis em dinheiro para a instituição de um lava-pés toda Quinta-Feira Santa, com fardamento dos pobres, e de um dote perpétuo anual para meninas órfãs. Finalmente, em 31 de junho de 1739, o capitão Francisco dos Santos e Marçal Magalhães Lima doaram cinqüenta e dois mil réis para a construção de um Recolhimento para donzelas órfãs e sustento das mesmas. As obras levaram cinco anos, e as primeiras órfãs foram recolhidas em 1743. 0 prédio então incorporado ao conjunto arquitetônico da Misericórdia foi construído à esquerda da Igreja da Misericórdia no largo de mesmo nome. Por sua vez, a Casa dos Expostos funcionou dentro do prédio das enfermarias do hospital até 1821, quando ganhou casa própria no largo da Misericórdia, em frente aos prédios mais antigos da irmandade.

O surgimento dessas novas repartições testemunha uma mudança de atuação da irmandade, que passa a se preocupar mais diretamente com a preservação das relações sociais e com 0 futuro do povoamento da cidade através do auxílio à infância e de maior atenção às instalações destinadas aos presos. Isso não significa que a irmandade tenha abandonado sua preocupação anterior com o hospital ou com as missas. Grande parte dos recursos da irmandade no período continuaram a ter sua origem na angústia dos homens e mulheres que, tementes por suas almas, investiam parte do patrimônio angariado durante a vida no cuidado com sua partida para o dia do Julgamento. Por conta disso, rezavam-se numerosas missas na igreja da Misericórdia, em favor de homens e mulheres, parentes e compadres, irmãos da Misericórdia e almas do purgatório.

A atenção com as almas e curas passou então a ser partilhada com as duas referidas instituições, o Recolhimento das Órfãs e a Casa dos Expostos. A primeira tinha por objetivo, segundo seus estatutos, abrigar meninas que fossem órfãs de pai e mãe, ou somente de pai, filhas legítimas, cristãs velhas, brancas, de bom procedimento, donzelas e desamparadas, com idades entre nove e 11 anos. Ainda segundo seus estatutos, "o principal fim deste Recolhimento, ... é o serviço de Deus, ... o aproveitamento espiritual e temporal das mesmas órfãs" (Algranti, 1997). 0 'aproveitamento' das moças significava conseguir-lhes um "estado", preferencialmente o de matrimônio, que tanto apetecia à I greja, sempre em busca de maior rebanho, e ao Estado português, preocupado em consolidar as populações de súditos em ultramar. A repartição organizava-se para oferecer, não sem grandes percalços e resistências, a doutrina espiritual e temporal das órfãs, a vigilância sobre suas honras e desordens, a concessão de dotes, o julgamento e a atribuição de pretendentes. As órfãs deveriam permanecer na instituição por tempo limitado, fixado em seis anos. Embora isso nem sempre acontecesse, a regra demonstra que a instituição se colocava como agenciadora da reinserção das

\footnotetext{
${ }^{3}$ Arquivo da Santa Casa da Misericórdia do Rio de Janeiro, "escritura de doação e instituição que faz Romão de Mattos Duarte à Santa Casa da Misericórdia para criação dos enjeitados", documentação avulsa, lata 35c.
} 
meninas na sociedade local, como mulheres preparadas para formarem unidades domésticas cristãs.

Já a chamada Casa dos Expostos possuía função bastante distinta. Eram consideradas expostas as crianças que não tinham filiação reconhecida. Em geral, eram abandonas nas igrejas, nas residências de pessoas de prestígio, na casas de parentes ou simplesmente deixadas nas ruas. Ao longo do século XVIII, a questão dos expostos tornou-se uma grande preocupação para os Estados modernos e, especificamente, para as elites que governavam aquela colônia portuguesa. A preocupação era sobretudo com que os contingentes de expostos fossem melhor aproveitados pelo Estado senão diretamente, nos exércitos por exemplo, ao menos no povoamento dos reinos. Por isso, a legislação, os hospitais e outras instituições se voltaram cada vez mais para soluções conjuntas que evitassem a mortandade dos expostos e promovessem sua inserção na sociedade. De acordo com a legislação, a responsabilidade pelo sustento dos expostos até completarem sete anos era das câmaras. 0 que elas em geral faziam era pagar amas-de-leite e amas secas para criarem as crianças em suas casas, e às vezes as amas as incorporavam como agregados a seus núcleos familiares. Após completarem sete anos, os expostos passavam à jurisdição dos juízes dos Órfãos, que deveriam encontrar famílias que os abrigassem, tomando-os como agregados ou aprendizes de algum ofício; no caso das meninas, encarregar-se-iam de sua tutela e, posteriormente, de seu casamento.

Instituições de caridade, como hospitais e irmandades, acabaram por auxiliar na criação dos expostos, algumas vezes trabalhando em conjunto com as câmaras e os juízes, outras vezes tendo de assumir integralmente a criação das crianças. A Casa dos Expostos da Santa Casa da Misericórdia do Rio de Janeiro pode ser incluída nesse contexto, tendo atuado com freqüência, sem os recursos da câmara, que demoravam a chegar. A Casa dos Expostos da Misericórdia adotou regime misto de acolhimento e distribuição das crianças por amas-deleite. Mantinha amas que deveriam dar socorro às crianças, assim que chegassem, e também sustentava amas de leite que cuidavam das crianças em suas casas. As que sobreviviam aos primeiros anos, e que não eram reclamadas pelos pais, acabavam sendo auxiliadas pela irmandade no acolhimento como agregadas em alguma família.

Podemos dizer que a atuação da irmandade no século XVIII era determinada pelas necessidades de uma cidade que enfrentava os problemas sociais de uma povoação urbana de Antigo Regime em plena consolidação. Além da questão da cura dos corpos e das almas, havia a preocupação com a pobreza, uma pobreza própria das sociedades do Antigo Regime: aquela ligada ao problema da privação dos laços comunitários, de parentesco, patronagem e clientela que permitissem a inserção dos indivíduos em núcleos familiares, corporações de ofício e irmandades e sua manutenção através deles. Por isso, os alvos da irmandade eram os órfãos, os expostos, os presos, as viúvas e outros deserdados. Para além da expressão pública de caridade cristã, o auxílio era um investimento na continuidade das relações desiguais e nas hierarquias sociais constituintes do Antigo Regime, assim como uma amortização das tensões sociais provocadas por tais relações. No caso do Recolhimento de Órfãs, 0 investimento no dote e casamento de meninas brancas e pobres liga-se ao esforço de manutenção da ordem social e a modos de pensar em que noções de "cor", "condição", "estado" e religião eram fundamentais à constituição do mundo católico luso-brasileiro. Todas as atividades cabiam no espaço daquele conjunto arquitetônico que unia igreja, hospital, Recolhimento e cemitério. As fronteiras físicas eram tênues, as necessidades estavam interligadas como estavam corpo e alma, todos sob o manto largo de Nossa Senhora da Misericórdia. 
O século XIX trouxe intenso questionamento do espaço e do perfil da Santa Casa. Em 1823, no primeiro ano do recém-criado Império do Brasil, por sugestão aparentemente da Assembléia Geral Constituinte, foi formada uma comissão composta por bacharéis, médicos e "autoridades" para informar à Secretaria de Estado dos Negócios do Império e à própria Assembléia em que estado se encontravam as diversas repartições da Santa Casa. As discussões, as tentativas de intervenção e as disputas de poder entre a comissão, os órgãos do governo e os irmãos administradores da Misericórdia se desenrolariam pelas décadas de 1820 e 1830.

Nas correspondências e relatórios então produzidos podemos notar que os prédios da Santa Casa passaram a ser vistos como incômodas inadequações às novas noções de higiene e planejamento. As múltiplas funções daquele amplo conjunto arquitetônico centralizado pela igreja da irmandade passam a ser consideradas o veículo de inúmeras contaminações físicas e morais. Em um relatório de 1824, podemos observar como os homens da Comissão se queixavam da intrincada configuração do espaço da irmandade. ${ }^{4}$ Em sua opinião, 0 hospital necessitava de novas enfermarias que possibilitassem tanto a convalescência dos doentes quanto 0 isolamento de doenças contagiosas. A cozinha não poderia permanecer no mesmo lugar porque a fumaça empesteava as enfermarias. A dos loucos não poderia mais ficar onde se encontrava, pois ali, no térreo, incomodavam os doentes que convalesciam nos andares superiores, e eram provocados por aqueles que transitavam nas ruas e nas passagens públicas que recortavam o espaço. A casa do Recolhimento das Ó rfãs era pequena e inadequada, sem espaço para que as meninas arejassem seus corpos, com a desvantagem ainda de que ficavam moralmente ameaçadas pela vizinhança dos quartéis.

Era preciso, portanto, fragmentar o espaço, fazer com que a arquitetura da Misericórdia fosse especializada para cada uma de suas funções. Aos loucos a companhia dos loucos, às donzelas a das donzelas e aos achacados disso ou daquilo. A cura e proteção dos corpos requeriam paredes, canos, ventilações e jardins internos, e não mais tanta proximidade com santos e rezas. Em 1835, a comissão apresentou à Secretaria de Estado dos Negócios do Império outro relatório avaliando as três principais repartições da irmandade: hospital, Recolhimento, Casa dos Expostos. Suas conclusões reiteravam a necessidade de espaços especializados.

Apesar dessas discussões, o espaço da Santa Casa sofreu poucas modificações até a chegada à provedoria de José Clemente Pereira. Advogado formado em Coimbra, um dos articuladores da independência, Clemente Pereira viria a participar no período imperial de legislaturas e da elaboração dos códigos criminal (1830) e comercial (1850). Seria ministro do Império. Tornou-se provedor da Santa Casa no ano de 1838, após ter sido conselheiro e mordomo dos presos. Durante sua provedoria, que se estendeu até 1854, foram feitas mudanças nas finanças da irmandade que redundaram em aumento da receita. A água foi introduzida nas três repartições da Santa Casa, criou-se um novo cemitério, um novo hospital, um hospício para os "loucos" e foram discutidas reformas nos regulamentos das repartições. Na gestão de Clemente Pereira, a configuração espacial da irmandade transformou-se definitivamente, iniciando-se a especialização dos espaços.

Logo ao assumir a provedoria, fez junto com os demais mesários uma visita de inspeção aos prédios. Bem ao estilo das comissões que vinham tentando intervir na irmandade, a

\footnotetext{
4 Arquivo Nacional, IS3-1 1824, documentação avulsa, Santa Casa da Misericórdia, "ofícios da comissão de conservação e melhoramentos da Santa Casa de Misericórdia do Rio de Janeiro".
} 
inspeção deu origem a um relatório com propostas de reforma do espaço. Relatório e sugestões foram apresentados em reunião da Mesa de irmãos. ${ }^{5}$ Como primeira medida, era preciso revogar os sepultamentos que se faziam no interior ou no adro da igreja da irmandade, e que deveriam passar a ser feitos em local mais afastado do hospital. Em 1853, em relatório à Mesa da irmandade, Clemente Pereira (1994, p. 35) recordaria as transformações do cemitério, deixando claro as preocupações higiênicas que tinham norteado as discussões desde a década de 1830:

A existência do cemitério dentro do hospital era uma verdadeira calamidade pública: a estatística dos corpos ali sepultados nos últimos oito anos apresenta o número de 22.279 , correspondente, termo médio, a 2.784 por ano; no ano findo, de 1o de julho de 1838 a 30 de junho de 1839, enterraram-se nele 3.194 corpos. E como fora possível que tão avultado número de cadáveres, amontoados em mal cobertas valas, deixassem de prejudicar, consideravelmente, não só a salubridade do hospital, mas mesmo a da cidade, achandose o cemitério fronteiro à barra, por onde entram ventos fortes e, com especialidade, a viração que antes de ir refrigerar a povoação, se embebia necessariamente nos miasmas pútridos daquele lugar?

Com a aprovação da Imperial Academia de Medicina da Corte, o campo santo da irmandade foi transferido para a chamada Ponta do Calafate, no Caju, e começou a funcionar em julho de 1839. Recomendava-se que os sepultamentos fossem executados com todo cuidado, e as covas elaboradas com a devida profundidade para que os corpos não revolvessem a terra.

O hospital, segundo Clemente Pereira, havia sido construído aos pedaços, conforme as necessidades do aumento da população e dos recursos, "sem atenção às condições recomendadas pelas regras de higiene". ${ }^{6}$ As enfermarias, principalmente as do andar de baixo, eram úmidas e sem circulação de ar. 0 provedor propôs a reforma do hospital seguindo um planejamento que seria aprovado pela Mesa, ficando, no entanto, a elaboração dos projetos e plantas a cargo da Academia Imperial de Medicina e da comissão de engenheiros escolhida pela irmandade.

Teve início nesta Mesa o projeto de construção do novo hospital da Misericórdia, obedecendo às regras de higiene. Na gesta da Mesa seguinte, foi escolhido o irmão marechal Cordeiro para levantar uma planta para o hospital com a ajuda dos engenheiros de sua confiança. Contando com a participação da Academia, a planta inicial foi elaborada pelo tenentecoronel Domingos Monteiro e a primeira pedra lançada em 1840. Enquanto se aguardava a construção do novo hospital, inovações eram feitas no velho e nas repartições da Casa dos Expostos e do Recolhimento das Órfãs. No velho hospital, a principal medida foi a criação de enfermarias separadas para doenças contagiosas.

$\mathrm{Na}$ Casa dos Expostos foram separados os internos sãos dos doentes, trocadas as roupas e demais utensílios utilizados nos cuidados das crianças, introduzida a amamentação artificial e criado um regimento interno para a administração do estabelecimento. Ele permaneceu junto ao Hospital Geral até 1821, quando foi adquirida uma casa própria no próprio largo da

\footnotetext{
${ }^{5}$ Livro de atas e termos das sessões e deliberações da administração da Santa Casa da Misericórdia do Rio de Janeiro nos annos de 1830-1840 (Rio de Janeiro, Typ. do Jornal do Commercio, de Rodrigues \& C., p. 327, 1914).

${ }^{6}$ Livro de atas e ter mos das sessões e deliberações da administração da Santa Casa da Misericórdia do Rio de Janeiro nos annos de 1830-1840 (Rio de Janeiro, Typ. do Jornal do Commercio, de Rodrigues \& C., p. 327, 1914).
} 
Misericórdia, de frente para a igreja da irmandade. A elevada mortalidade e morbidade entre as crianças, a busca por espaços que correspondessem aos ideais da higiene e os recursos muitas vezes escassos fizeram com que a repartição saísse em jornada pela cidade. Deixando a casa do Largo da Misericórdia, os expostos foram transferidos para a rua de Santa Teresa em 1850; para uma casa na rua da Lapa, no cais da Glória, no ano de 1860; em seguida, para a rua dos Barbonos, até 1906; daí para duas casas no Flamengo até 1911; por fim, neste mesmo ano, para o prédio na rua Marquês de Abrantes, que se transformou na sede definitiva da Casa dos Expostos, desde então denominada Educandário Romão de Mattos Duarte, em homenagem a seu fundador setecentista.

No Recolhimento das Ó rfãs também foram feitas obras, aumentando seu espaço interior e diminuindo sua comunicação com as vielas públicas. Os estatutos foram reformulados e os valores dos dotes, elevados. 0 Recolhimento permaneceria junto ao hospital somente até 0 ano de 1842, quando teve início igual peregrinação pela cidade, passando da instituição por vários prédios, algumas vezes separando-se as órfãs sãs das enfermas, em Laranjeiras, Botafogo, São Cristóvão e por fim, em 1866, de volta a Botafogo, na rua General Severiano, como veremos mais adiante.

Paralelamente, começou a ser discutida a possibilidade de se criar um hospital próprio para os alienados a ser administrado pela Santa Casa. Em reunião no dia 24 de agosto de 1841, foi lido decreto de Pedro II, em resposta a uma representação de Clemente Pereira, no qual autorizava a criação de um hospício para alienados que levaria seu nome, em celebração a sua coroação como imperador. Naquela reunião, os irmãos deliberaram criar uma administração específica para o hospício, que seria edificado numa chácara pertencente à irmandade, na Praia Vermelha, onde já funcionava uma enfermaria para mulheres. A construção do prédio ficaria por conta de contribuição do imperador e de subscrições voluntárias de cidadãos, ${ }^{7}$ que, segundo nos conta Vieira Fazenda (1960, p. 178), seriam recompensados com títulos e condecorações conhecidas como "impostos à vaidade". 0 expediente parece ter sido eficaz, pois viabilizou em parte a construção do prédio do hospício. Tendo sido colocada a primeira pedra em 1842, foi inaugurado em 1852, ficando definitivamente concluídas as obras em 1855.

Em 1852, foi inaugurado em espaçoso terreno na rua de Santa Luzia o novo Hospital Geral da Misericórdia, afastado do cemitério e da convivência com os loucos. A inauguração foi celebrada no dia de santa Isabel, mas o prédio dava agora as costas para a igreja de Nossa Senhora do Bonsucesso.

Os hospitais da Misericórdia passariam a contar, naquele mesmo ano, com novo contingente de pessoas em seus corredores: as irmãs de caridade. Foi mais um dos atos transformadores da provedoria de Clemente Pereira, que negociou com a Ordem de São Vicente de Paula de Paris o envio das religiosas para auxiliar os médicos nas funções de enfermaria e farmácia. Segundo Zarur (1996, p. 17), o primeiro grupo de irmãs chegou à cidade do Rio de Janeiro em setembro de 1852, portanto em meio às grandes epidemias que nela grassaram desde fins da década de 1840, especificamente a febre amarela (1849-50) e o cólera (1855). A presença das irmãs de caridade viabilizava economicamente 0 atendimento a grande número de pessoas infectadas, auxiliava a concretização do

\footnotetext{
${ }^{7}$ Livro de atas e termos das sessões e deliberações da administração da Santa Casa da Misericórdia do Rio de Janeiro nos annos de 1830-1840 (Rio de Janeiro, Typ. do Jornal do Commercio, de Rodrigues \& C., p. 54, 1915).
} 


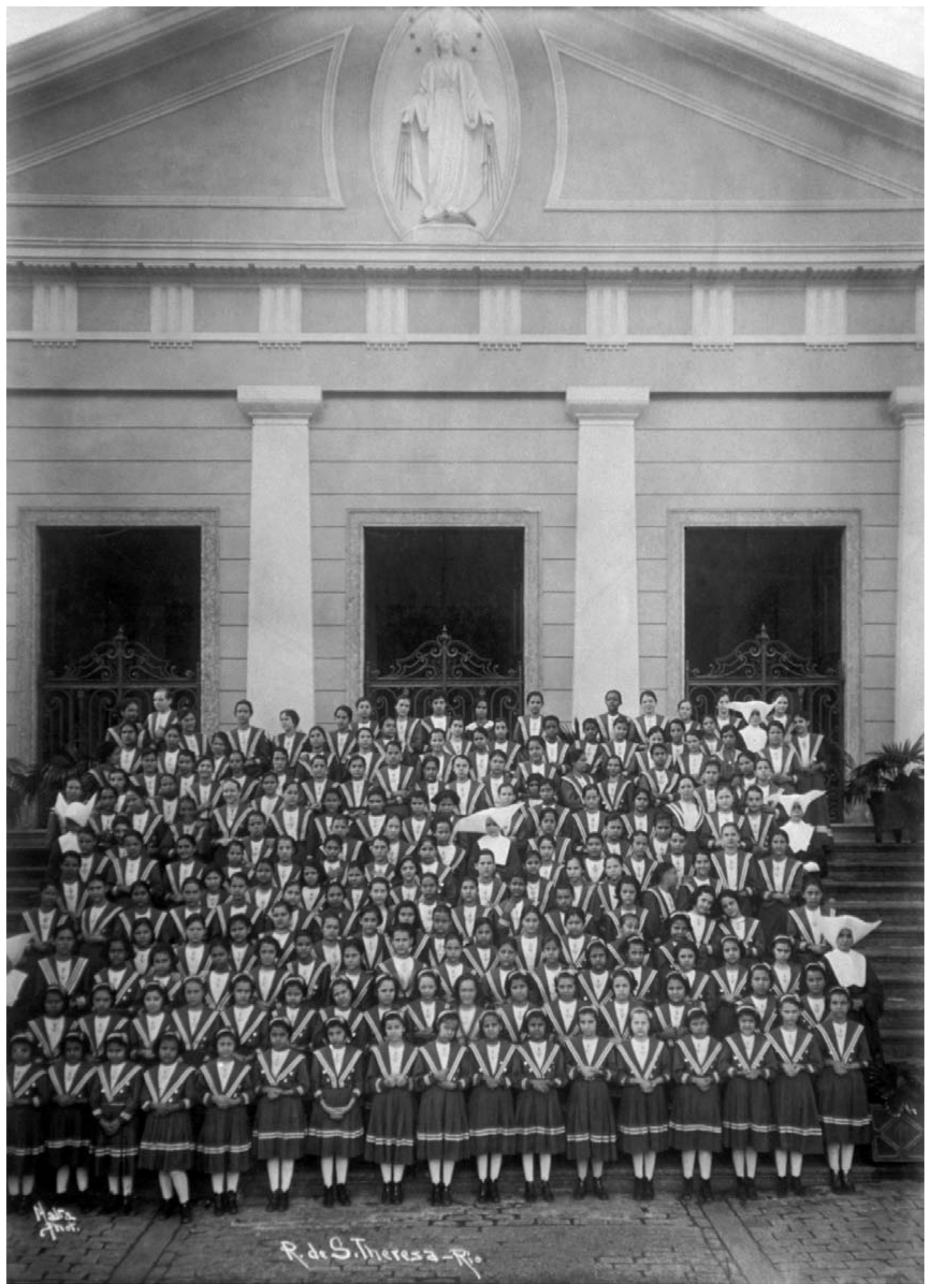

Prédio do Recolhimento das Órfãs de Santa Tereza, que abrigou milhares de meninas (acervo do Museu da Imagem e do Som - MIS). 


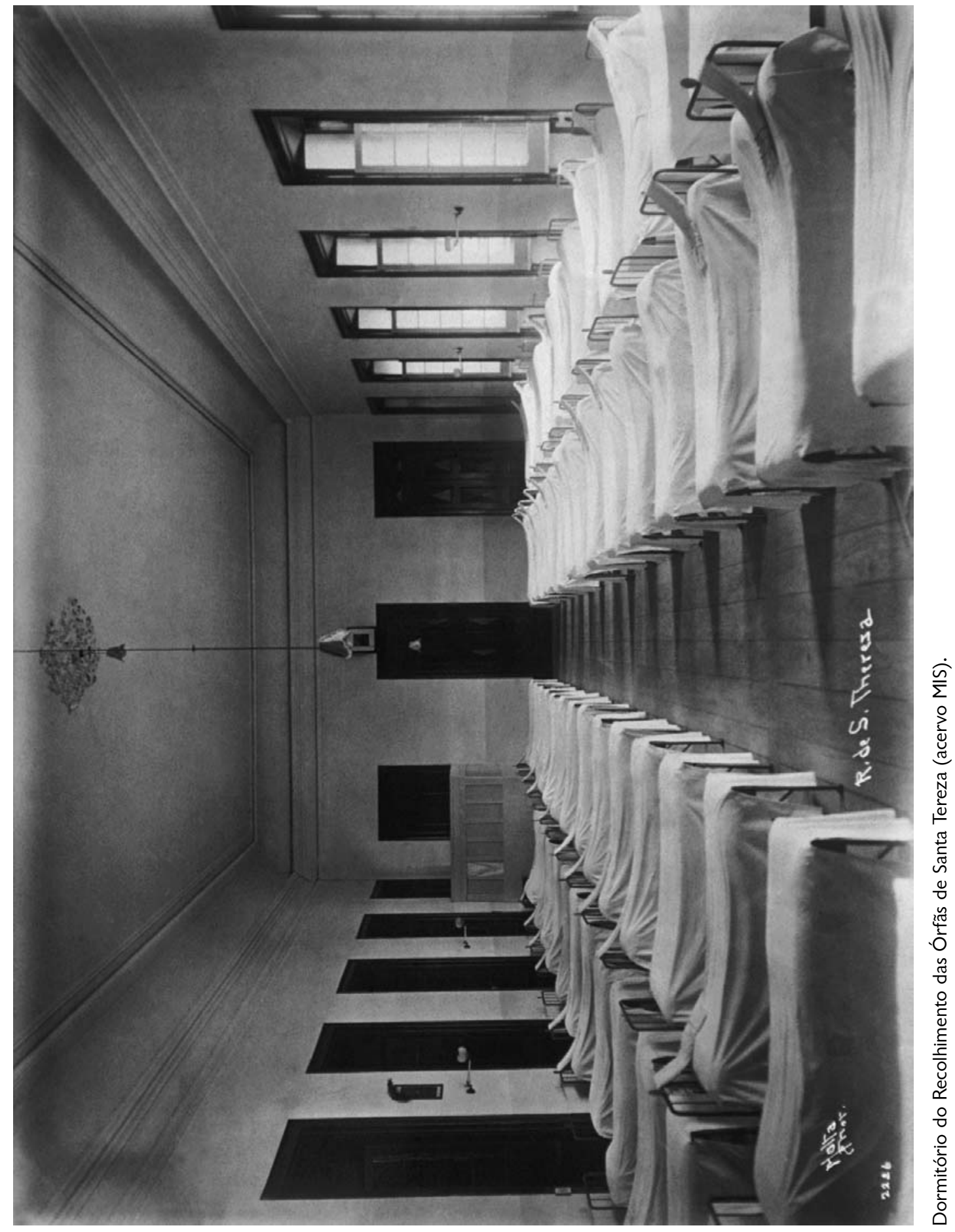

622 HISTÓRIA, CIÊNCIAS, SAÚDE VOI. VIII(3) 


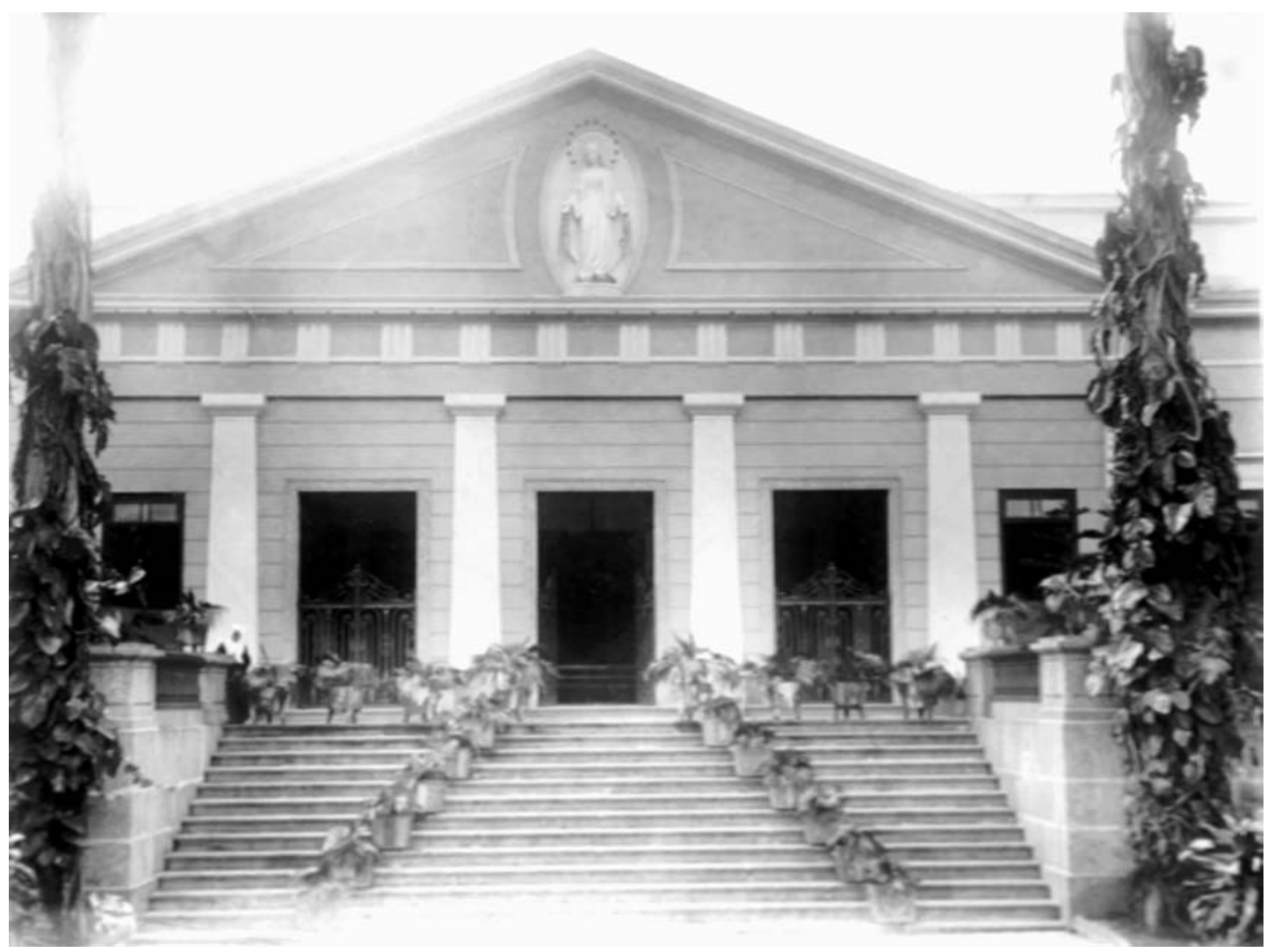

Fachada do prédio do Recolhimento das Órfãs de Santa Tereza (acervo MIS).

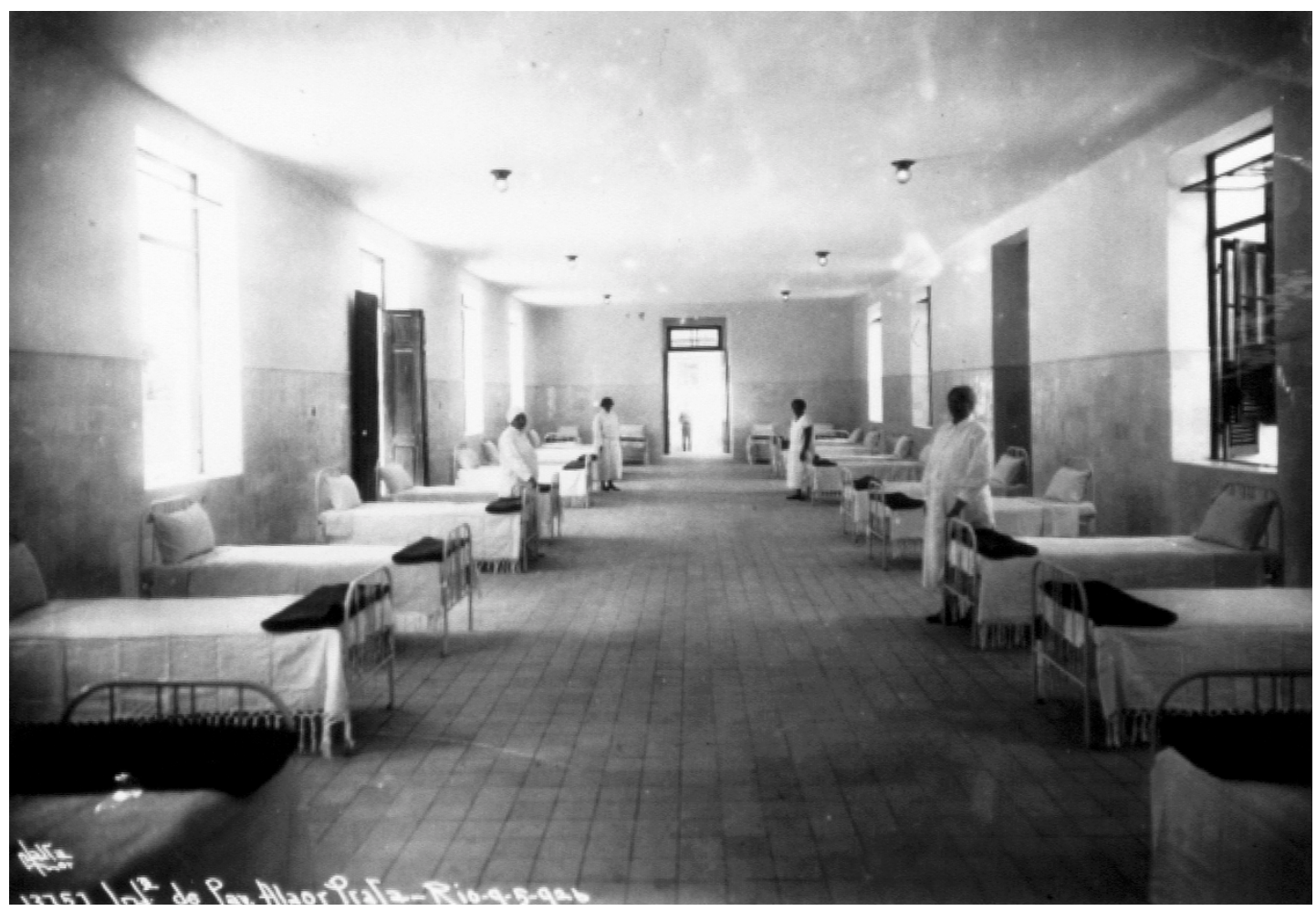

Enfermaria do Hospício d. Pedro II (acervo Arquivo Geral da Cidade do Rio de Janeiro - AGCRJ). 
Fachada do

prédio do

Hospício

d. Pedro II

(acervo AGCRJ).
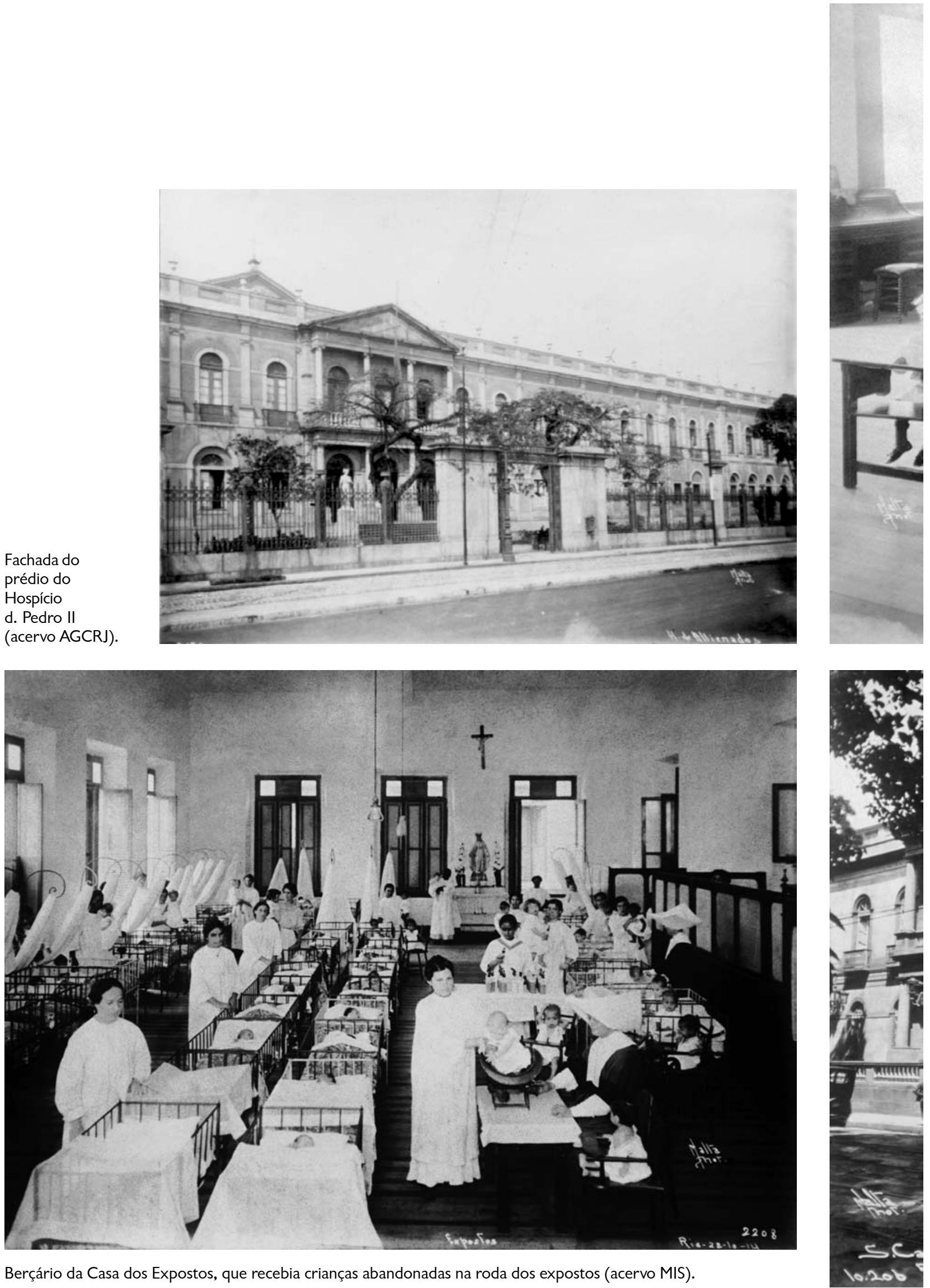

Berçário da Casa dos Expostos, que recebia crianças abandonadas na roda dos expostos (acervo MIS). 


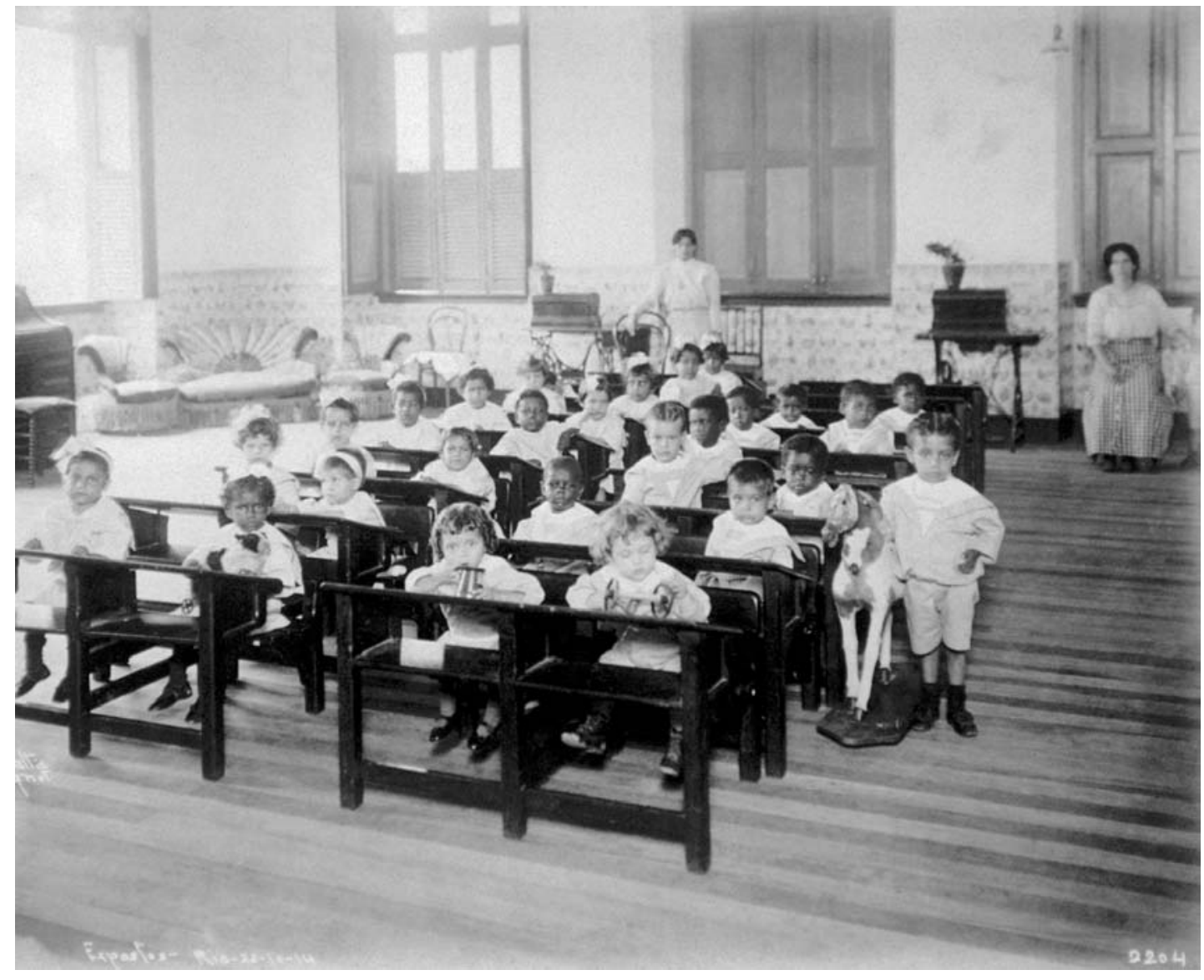

Sala de aula da Casa dos Expostos, hoje denominada Fundação Romão Duarte (acervo MIS).

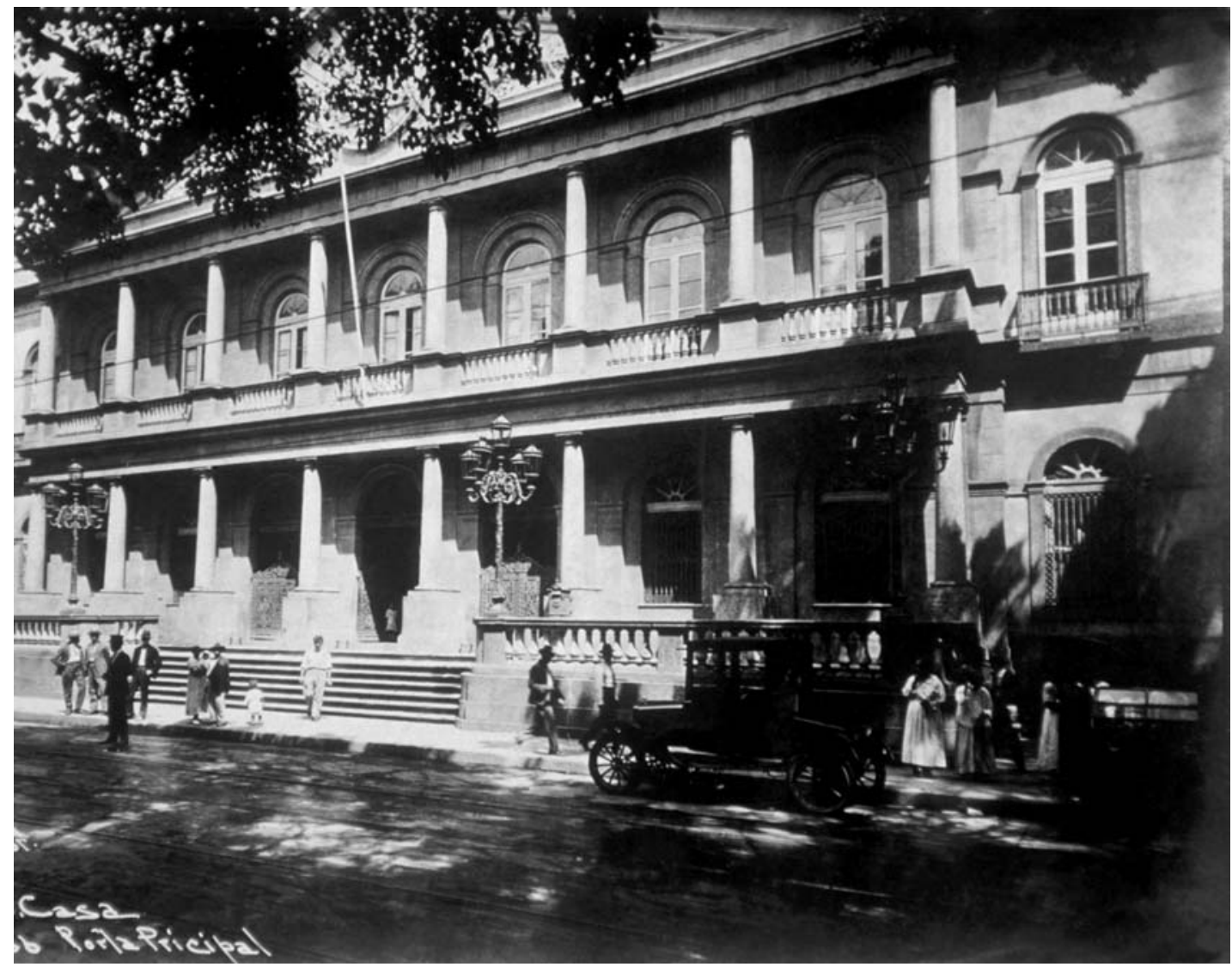

Porta principal da

Santa Casa da

Misericórdia

(acervo AGCRJ). 


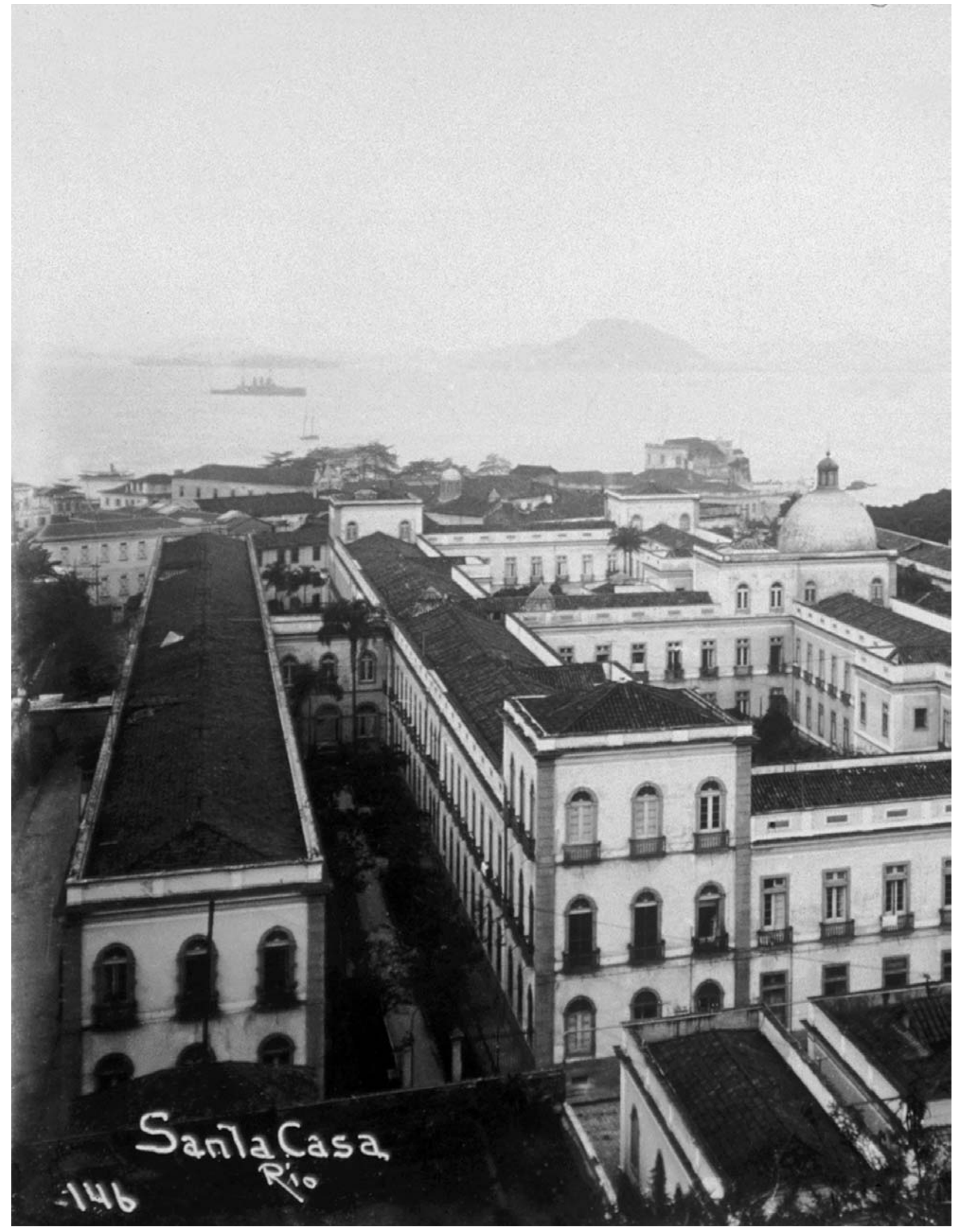




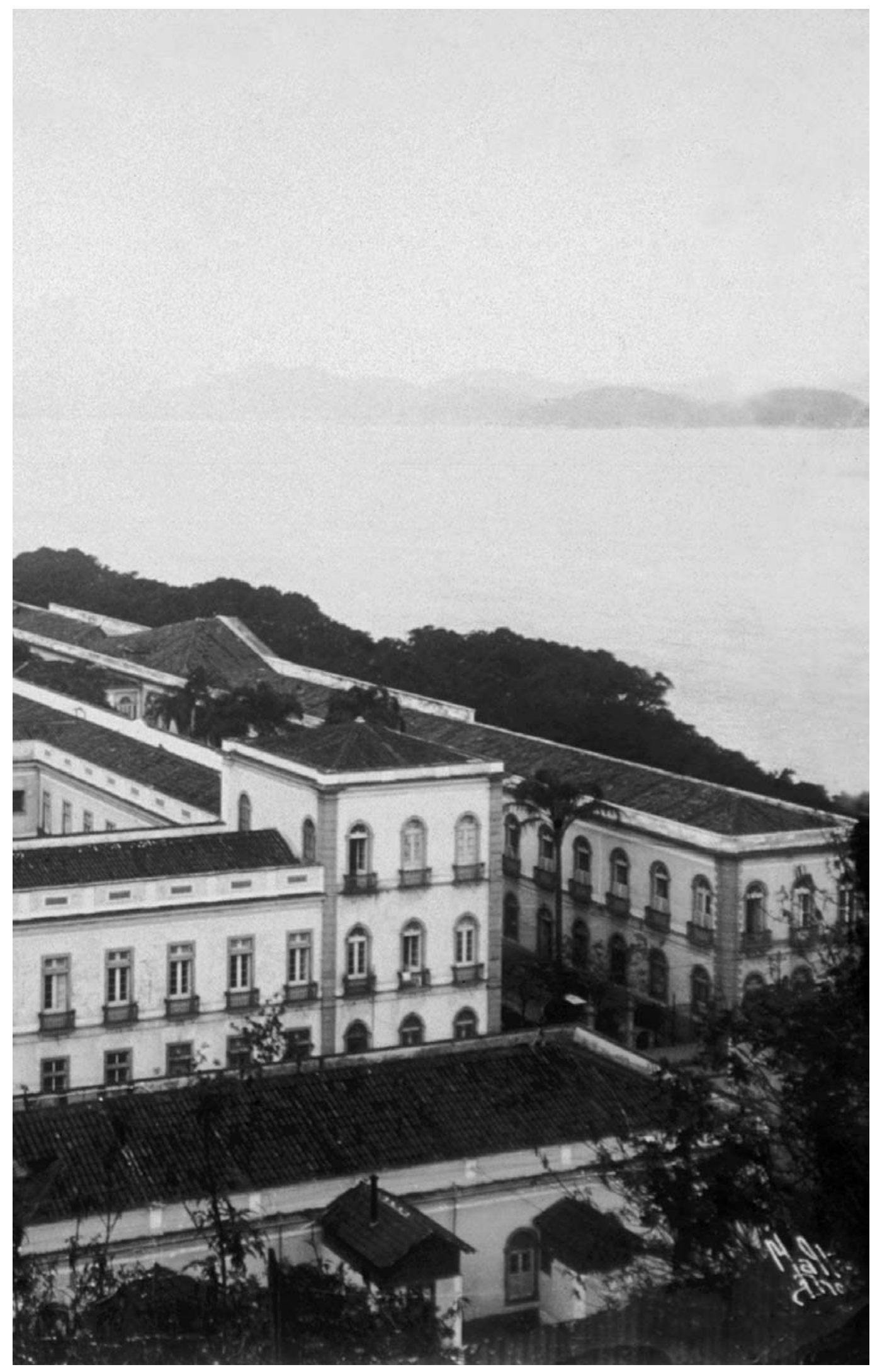

Santa Casa da

Misericórdia

retratada do Morro

do Castelo

(acervo AGCRJ). 


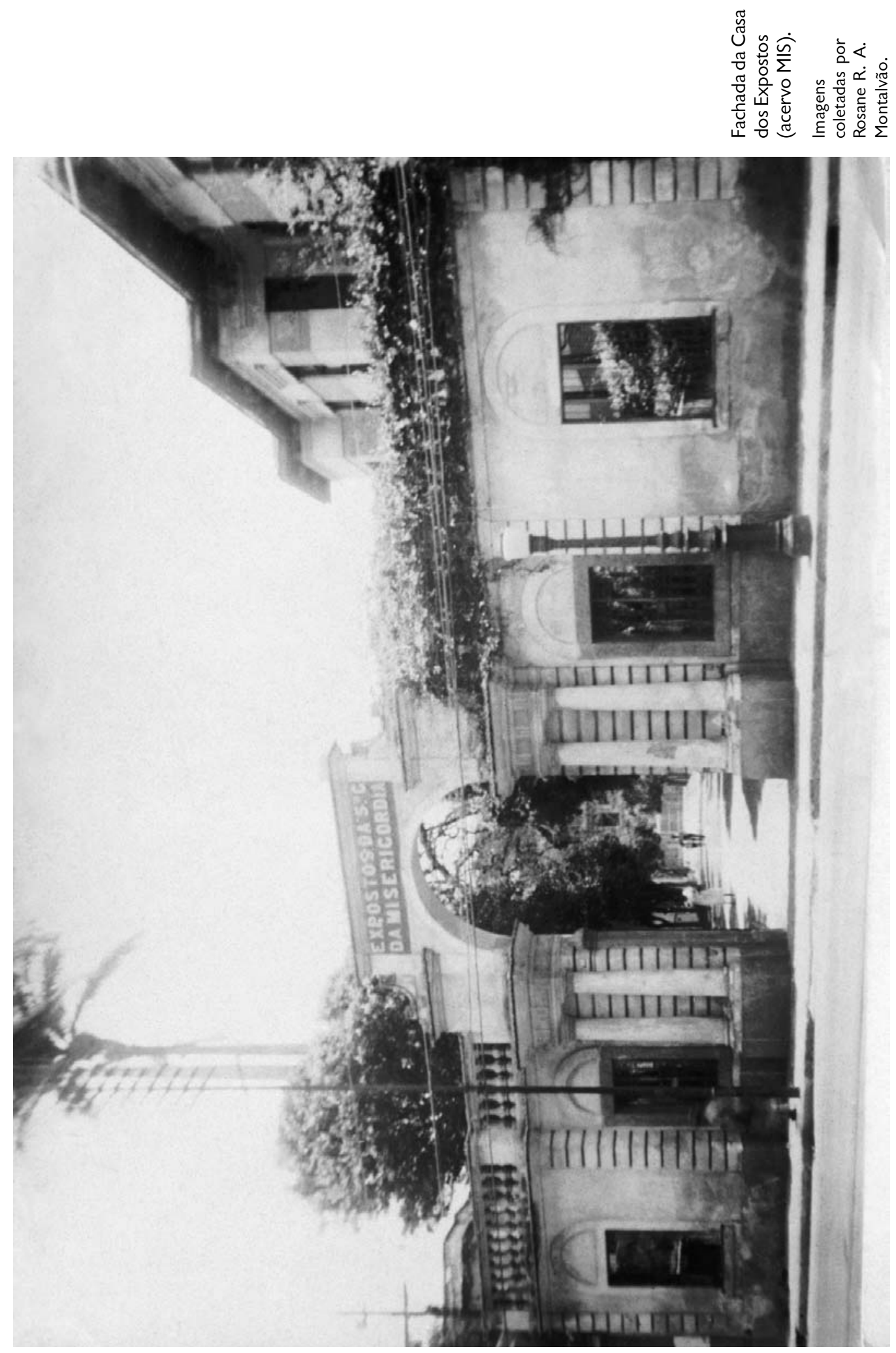


projeto de separação dos doentes contagiosos assim como o alargamento da atuação da irmandade pelo espaço da cidade. Este foi um período em que ela adquiriu vários pequenos prédios, transformando-os em enfermarias ou pequenos hospitais. Foi o caso, por exemplo, do Hospital de Nossa Senhora da Saúde, na Gamboa, inaugurado em 1853 para acolher as vítimas das duas epidemias.

O século XIX presenciou, assim, grandes mudanças na configuração dos espaços destinados à caridade e na forma como esta era executada. No ano de 1851, o Ministério dos Negócios do Império entrou em contato com a irmandade com o intuito de estabelecer, segundo a vontade do Imperador d. Pedro II, um asilo para menores desvalidas que não fossem órfãs e que, portanto, não poderiam ser admitidas no Recolhimento já existente. Em 1852 foi criado o Amparo às Meninas Desvalidas, sob administração da Misericórdia e aos cuidados das irmãs de caridade de São Vicente de Paula. Ainda na provedoria de José Clemente Pereira, o Amparo e o Recolhimento das Ó rfãs da Misericórdia foram unificados. A união física das instituições, entretanto, foi conseguida em definitivo no ano de 1866 com a construção do prédio na rua General Severiano que recebeu o nome de Recolhimento das Ó rfãs e Desvalidas de Santa Teresa. Atualmente chama-se apenas Educandário de Santa Teresa. Tal reconfiguração veio acompanhada de mudanças na maneira como se pensava a caridade para com as órfãs e as chamadas desvalidas, ainda que estas mudanças não tenham sido lineares e efetuadas sem conflitos.

José Clemente Pereira faleceu em 1854, ainda no cargo de provedor. Pode-se dizer que sua provedoria transformou o perfil da irmandade, dando o tom às gestão das provedorias subseqüentes. A característica da gestão de Clemente Pereira foi a fragmentação das repartições da irmandade e sua distribuição pela cidade, acompanhando sua expansão e urbanização. Mais do que simples deslocamentos, tais transformações representaram paulatina concentração da irmandade em atividades hospitalares, até que essas atividades e seu nome se transformassem em sinônimos, legando às demais repartições denominações à parte. A atuação dos irmãos foi reduzida a instâncias administrativas, e a importância de sua aparição pública em cerimônias e festas religiosas foi reduzida por efeito da racionalidade que punha em primeiro plano a cura, os investimentos em medicamentos e na medicalização dos corpos. 0 grande conjunto arquitetônico da rua de Santa Luzia e, portanto, a própria irmandade passaram a ser dominados por seu hospital. As demais repartições distribuídas por prédios da cidade orbitariam como satélites distantes, marcados pela especialização de funções. 0 chamado Campo Santo da Misericórdia foi transferido para sítio distante no Caju, e aos poucos se desdobraria em vários cemitérios de denominações diferentes.

Como observou João do Rio, a trajetória da irmandade acompanhou a história da cidade. Pela estreita relação que manteve ao longo de três séculos, nem sempre pacífica ou subserviente, com os projetos de governo, com governantes e membros da elite, a Santa Casa é um privilegiado campo de observação das políticas dessa "elite" com relação à cidade e seus pobres. Mais do que simples resposta ao crescimento da população, as mudanças sofridas no espaço, organização e atuação da irmandade corresponderam às modificações de diversas naturezas ocorridas na sociedade, econômicas e políticas, religiosas e simbólicas. À medida que a cidade deixa de correr inteira pela rua da Misericórdia, e de dar em sua igreja, a irmandade acompanha as suas frentes de expansão, tornando-se palco ou objeto de candentes discussões e de projetos que influenciaram de maneira significativa as transformações sociais e urbanas ocorridas no século XIX. 


\section{REFERÊNCIAS BIBLIOGRÁFICAS}

\begin{tabular}{|c|c|}
\hline $\begin{array}{c}\text { Algranti, Leila Mezan } \\
1997\end{array}$ & $\begin{array}{l}\text { 'O s estatutos do Recolhimento das Ó rfãs da Santa Casa da Misericórdia do } \\
\text { Rio de Janeiro'. Cadernos Pagu: gênero, narrativas, memórias. } \\
\text { Campinas, Núcleo de Estudos de Gênero, 8-9. }\end{array}$ \\
\hline $\begin{array}{l}\text { Ferreira, Felix } \\
\qquad 1894-98\end{array}$ & $\begin{array}{l}\text { A Santa Casa da Misericórdia Fluminense. } \\
\text { Rio de Janeiro, Santa Casa da Misericórdia. }\end{array}$ \\
\hline $\begin{array}{l}\text { Ferrez, Gllberto (org.) } \\
\text { s. d. }\end{array}$ & $\begin{array}{l}\text { O velho Rio de Janeiro através das gravuras de Thomas En der. } \\
\text { São Paulo, Melhoramentos, p. } 25 .\end{array}$ \\
\hline $\begin{array}{l}\text { Guimarães Sá, Isabel dos } \\
1995\end{array}$ & $\begin{array}{l}\text { A circulação de crianças na Europa do sul: o caso dos expostos do Porto } \\
\text { no século XVIII. Lisboa, Fundação Calouste Gulbenkian. }\end{array}$ \\
\hline $\begin{array}{l}\text { Pereira, José Clemente } \\
1994\end{array}$ & $\begin{array}{l}\text { Reunião de } 25 \text { de julho de 1835, apud Dahas Zarur, } \\
\text { A vida dos mortos. Rio de Janeiro, Binus, p. } 35 .\end{array}$ \\
\hline $\begin{array}{r}\text { Reis, João José } \\
1999\end{array}$ & $\begin{array}{l}\text { A morte é uma festa: ritos fúnebres e revolta popular no Brasil do século XIX. } \\
\text { São Paulo, Companhia das Letras. }\end{array}$ \\
\hline $\begin{array}{c}\text { Rodrigues, Cláudia } \\
1997\end{array}$ & $\begin{array}{l}\text { Lugares dos mortos na cidade dos vivos. } \\
\text { Rio de Janeiro, Secretaria Municipal de Cultura, Departamento Geral de } \\
\text { Documentação e Informação Cultural, Divisão de Editoração. }\end{array}$ \\
\hline $\begin{array}{l}\text { Russell-Wood, A. J. R. } \\
1981\end{array}$ & $\begin{array}{l}\text { Fidalgos efilantropos: a Santa Casa da Misericórdia da Bahia, 1550-1775. } \\
\text { Brasília, Editora Universidade de Brasília. }\end{array}$ \\
\hline $\begin{array}{l}\text { Santa Maria, } \\
\text { Frei Agostinho de } \\
\qquad 1723\end{array}$ & $\begin{array}{l}\text { Santuário Mariano e histórias das imagens milagrosas de Nossa Senhora e } \\
\text { milagrosamente aparecidas. Lisboa, Officina de Antônio Pedrozo Galrão, vol. } 10 .\end{array}$ \\
\hline $\begin{array}{l}\text { Santos, Luiz Gonçalves } \\
\text { dos (Padre Perereca) } \\
1981\end{array}$ & $\begin{array}{l}\text { Memórias para servir à história do reino do Brasil. } \\
\text { Belo Horizonte/São Paulo, Itatiaia/Edusp. }\end{array}$ \\
\hline $\begin{array}{l}\text { Vasconcellos, padre } \\
\text { Simão de } \\
\qquad 1906\end{array}$ & $\begin{array}{l}\text { Vida do venerável padre José de Anchieta, apud José Vieira Fazenda, 'A Santa } \\
\text { Casa da Misericórdia do Rio de Janeiro', em RIHGB, tomo 69, volume } 113 .\end{array}$ \\
\hline $\begin{array}{l}\text { Vieira Fazenda, José } \\
1960\end{array}$ & $\begin{array}{l}\text { Os provedores da Santa Casa da Misericórdia do Rio de Janeiro. } \\
\text { Rio de Janeiro, s. ed. }\end{array}$ \\
\hline $\begin{array}{r}\text { Zarur, Dahas } \\
1996\end{array}$ & $\begin{array}{l}\text { ssa Senhora da Saúde. } \\
\text { Binus. }\end{array}$ \\
\hline
\end{tabular}

